\title{
Electrokinetic treatment on a tropical residual soil
}

1 Kamarudin Bin Ahmad PhD

Associate Professor, Faculty of Civil Engineering, Universiti Teknologi Malaysia, Skudai, Johor, Malaysia

2 Mohd. Raihan Taha PhD

Professor, Department of Civil and Structural Engineering, Universiti Kebangsaan Malaysia, Bangi, Selangor, Malaysia
3. Khairul Anuar Kassim PhD

Professor, Faculty of Civil Engineering, Universiti Teknologi Malaysia, Skudai, Johor, Malaysia
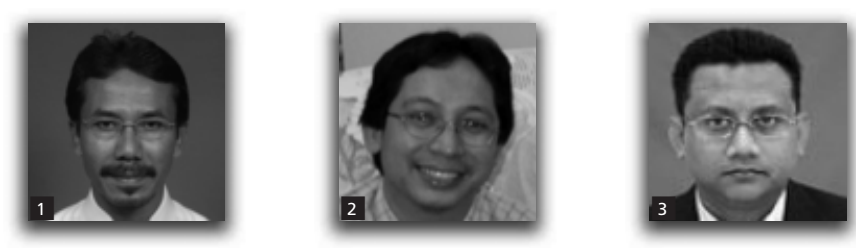

The results of shear box and consolidation tests on electrokinetically-treated tropical residual soil are presented. Injections of selected chemicals (calcium chloride, aluminium chloride and phosphoric acid) into the soil samples at the anodes or cathodes were carried out in cylindrical electrokinetic cells via applications of $30 \mathrm{~V}$ DC electrical potential for $168 \mathrm{~h}$. Four different open-anode and open-cathode electrokinetic systems utilising different anolytes and catholytes were employed to treat the soil samples. The shear resistances of the treated soil utilising distilled water as the anolyte and $1.0 \mathrm{~mol} / \mathrm{l}$ phosphoric acid as the catholyte was enhanced, whereas the treated soil near the cathode showed significant reduction in compressibility. Soil treated utilising the other chemicals showed no significant changes.

\section{Notation}

$C_{\mathrm{c}} \quad$ compression index

$C_{\mathrm{s}} \quad$ swelling index

$c_{\mathrm{V}} \quad$ coefficients of consolidation

ele $e_{0}$ normalised void ratio

$k \quad$ hydraulic conductivity

$m_{\mathrm{v}} \quad$ average volume compressibility

$w_{\mathrm{opt}}$ optimum moisture content

$\sigma_{\mathrm{y}} \quad$ yield stresses

$\sigma_{\mathrm{c}} \quad$ pre-consolidation pressures

$\rho_{\text {dmax }}$ dry density

\section{Introduction}

Several methods have been employed worldwide to improve the engineering characteristics of soils so as to increase shear strength and to reduce compressibility. Such methods can be categorised into different classes of stabilisation, namely mechanical, chemical, thermal and electrical. With regard to tropical residual soils, the shear strength decreases and the compressibility increases when the soils are saturated. Reductions of up to $50 \%$ in cohesion intercept and about $30 \%$ in internal shear resistance as a result of saturation of lateritic soils were reported by Sridharan (1988).

In relation to electrochemical treatment to stabilise soils, chemicals are introduced at the anode or/and cathode, either in solution or by decomposition of the electrodes. As a result, the treated soil is strengthened due to the formation of cementing compounds that are highly resistant to shear and deformation. In the present state, most electrokinetic (EK) processing is performed on soils of temperate zones, particularly kaolinite. Therefore, a laboratory study was initiated to investigate the effects of types of anolyte and catholyte on the shear resistance and compressibility of an electrokinetically-treated Malaysian granite residual soil. Enhancement of the engineering properties was anticipated by precipitation of the introduced ions.

\section{Electrokinetics}

Electrokinetic phenomena in a porous medium are basically based on the relative motion between a charged surface and the bulk solution at its interface. The formation of an electric double layer at the charged surface of clay particles is responsible for EK phenomena of interest, namely electrophoresis, electromigration and electroosmosis (Mitchell, 1993).

In electroosmosis, electrolysis of water at the anode and the cathode produces oxygen and hydrogen, respectively, which can be represented by the following equations:

1. $2 \mathrm{H}_{2} \mathrm{O}-4 \mathrm{e}^{-} \rightarrow 4 \mathrm{H}^{+}+\mathrm{O}_{2} \uparrow \quad$ anode

2. $2 \mathrm{H}_{2} \mathrm{O}+2 \mathrm{e}^{-} \rightarrow 2 \mathrm{OH}^{-}+\mathrm{H}_{2} \uparrow \quad$ cathode 
Based on Equations 1 and 2, it is noteworthy that both $\mathrm{H}^{+}$and $\mathrm{OH}^{-}$migrate across the soil sample towards the cathode and the anode, respectively during the course of EK processing. In addition, many complicated electrochemical phenomena that are dynamic, reversible and interdependent can change the EK properties of soil particles and the chemistry of pore fluid simultaneously (Yeung and Hsu, 2005).

Low permeability soils which cannot be successfully drained by methods such as sheeting and open pumping can be drained with the help of electrical flow (Chappell and Burton, 1975). Several researchers (Esrig, 1968; Johnston and Butterfield, 1977; Othman and Shafii, 1990) had conducted bench-scale experiments to investigate the effects of electroosmosis on engineering properties of soils, while field tests performed by other researchers (Chappell and Burton, 1975; Fetzer, 1967; Lo and Ho, 1991) justified the applicability of the process.

Electrokinetic processing has also been employed with the combination of chemical solutions to increase strength of low hydraulic conductivity cohesive soils. These chemical solutions can be fed at the anode or the cathode depending upon the ions to be transferred into the soil. The chemical substances utilised include among others calcium chloride (Barker et al., 2004; Harton et al., 1967), aluminium chloride (Gray, 1970), sodium silicate (Barker et al., 2004) and aluminium sulfate and phosphoric acid (Ozkan et al., 1999).

\section{Soil properties}

The particle size distribution of the soil used in this study as obtained based on sieve analysis and hydrometer test is illustrated

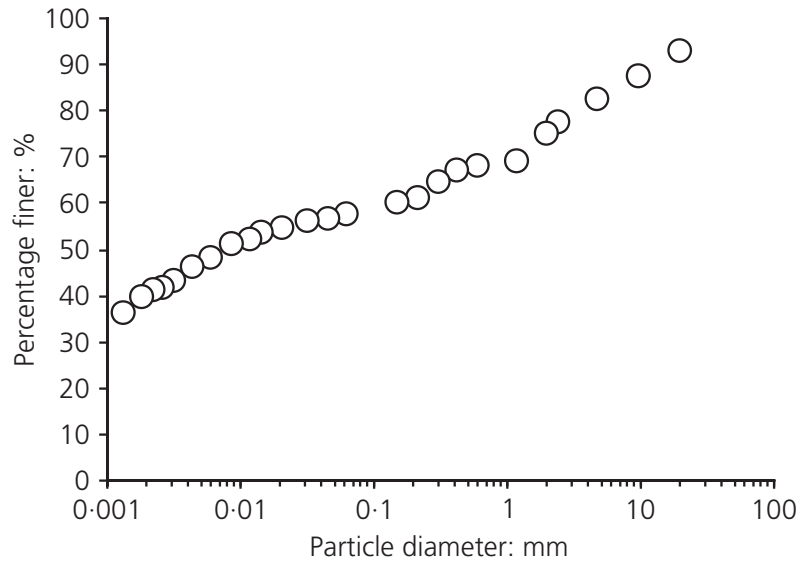

Figure 1. Particle size distribution of soil

in Figure 1 and the basic engineering and chemical properties are tabulated in Table 1. This soil was classified as silt of very high plasticity with gravel (MVG) based on BS 1377: Part 2 (BSI, 1990a). The ratio of silicon dioxide $\left(\mathrm{SiO}_{2}\right)$ to aluminium oxide $\left(\mathrm{Al}_{2} \mathrm{O}_{3}\right)$ yielded a value of 1.01 indicating that the soil used in this study is a laterite (Mitchell, 1993).

X-ray diffraction (XRD) analysis was performed in which a powder-like ground soil sample was analysed for its compounds using a diffractometer. The diffractogram was redrawn as shown in Figure 2 and was referred to the Joint Committee on Powder Diffraction Standards (Berry, 1974) for mineral identification. The result showed that the predominant minerals present were kaolinite, quartz, gibbsite and goethite.

\begin{tabular}{lcl}
\hline Properties & Values & References/methods \\
\hline Specific gravity & $2 \cdot 71$ & BS 1377: Part 2:1990 (BSI, 1990a) \\
Natural moisture content: \% & $3 \cdot 65$ & BS 1377: Part 2:1990 \\
Liquid limit: \% & $74 \cdot 50$ & BS 1377: Part 2:1990 \\
Plastic limit: \% & $49 \cdot 00$ & BS 1377: Part 2:1990 \\
Plasticity index: \% & $25 \cdot 50$ & BS 1377: Part 2:1990 \\
Shrinkage limit: \% & $18 \cdot 31$ & BS 1377: Part 2:1990 (volumetric) \\
pH & $5 \cdot 30$ & BS 1377: Part 3:1990 (BSI, 1990b) \\
Organic: \% & $2 \cdot 00$ & BS 1377: Part 3:1990 (peroxide) \\
Chloride: \% (water soluble) & $0 \cdot 012$ & BS 1377: Part 3:1990 (UV visible) \\
Sulfate: \% (water extract) & $5 \cdot 85$ & BS 1377: Part 3:1990 (UV visible) \\
Carbonate: \% & $0 \cdot 20$ & BS 1377: Part 3:1990 (UV visible) \\
Maximum dry density: kg/m ${ }^{3}$ & $1415 \cdot 00$ & BS 1377: Part 4:1990 (BSI, 1990c) \\
Optimum moisture content: \% & $33 \cdot 00$ & BS 1377: Part 4:1990 \\
Hydraulic conductivity: $\mathrm{m} / \mathrm{s}$ & $3 \cdot 60 \times 10^{-8}$ & Head (1982) \\
CEC: meq/100 g soil & $1 \cdot 00$ & Moris and Singh (1980) \\
AEC: meq/100 g soil & $1 \cdot 30$ & Hesse (1972) \\
\hline
\end{tabular}

CEC, cation exchange capacity; AEC, anion exchange capacity

Table 1. Engineering and chemical properties of the soil 


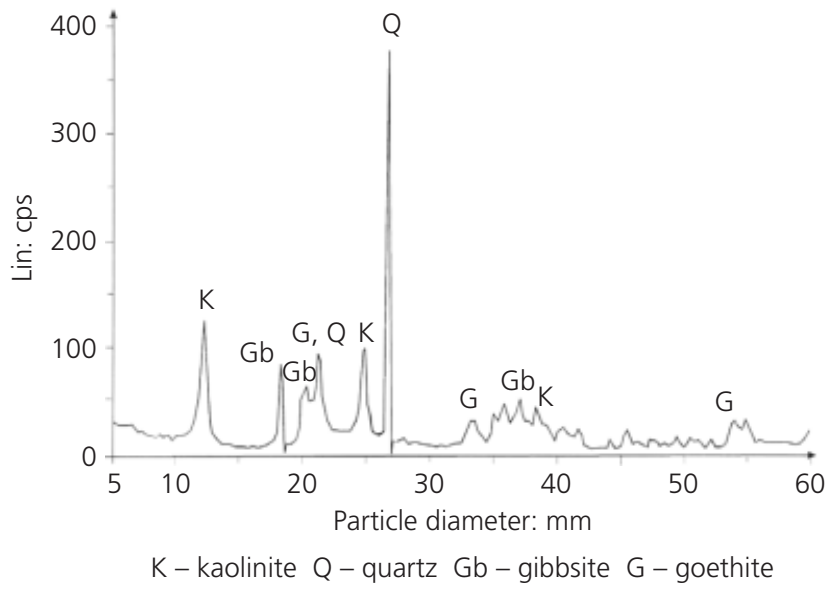

Figure 2. Redrawn diffractogram of residual soil used in this study

From measurements made based on BS 1377: Part 3 (BSI, 1990 b) with slight modification to suit the EK cell, it was learnt that the average resistivity of the compacted and saturated samples (C\&S) was approximately $1 \times 10^{5} \Omega \mathrm{cm}$, higher than the range of values from $5 \times 10^{2}$ to $5 \times 10^{4} \Omega \mathrm{cm}$ as reported by geophysicists (Hausmann, 1990). The high resistivity, low cation exchange capacity (CEC) and anion exchange capacity (AEC) of the soil might be associated with the intensive weathering and the high annual rainfall (between 1700 and $3500 \mathrm{~mm}$ ) that leached away the dissolved constituents from the soil (Gidigasu, 1976). Nonetheless, the low value of the CEC obtained in this study was in general agreement with soils containing high iron and aluminium oxides (Brady and Weil, 1996).

The procedures to determine the CEC are described by Moris and Singh (1980). In this regard, a soil sample was left inundated overnight in $1.0 \mathrm{~mol} / 1 \mathrm{ammonium}$ acetate in a flask after which the valve of the flask was opened slightly so that the liquid dripped slowly. The liquid collected was analysed for calcium $\left(\mathrm{Ca}^{2+}\right)$, magnesium $\left(\mathrm{Mg}^{2+}\right)$, sodium $\left(\mathrm{Na}^{+}\right)$and potassium $\left(\mathrm{K}^{+}\right)$ using an atomic adsorption spectrophotometer (AAS).

The AEC was determined based on the quantity of extractable and adsorbed phosphorus as described by Hesse (1972). In summary, the dry soil sample was leached with triethanolamine solution and washed using ethanol. The sample was dried after leaching with calcium chloride and was agitated after adding $0.01 \mathrm{~mol} / 1$ of phosphoric acid. Then the liquid was analysed using AAS to determine the adsorbed phosphorus.

In a separate sample, the phosphorus was extracted using $0.03 \mathrm{~mol} / \mathrm{l}$ ammonium fluoride in $0.1 \mathrm{~mol} / 1$ hydrochloric acid. A soil/solution ratio of 1:20 was applied in the extraction process. The mixture was shaken and filtered, after which the content of phosphorus in the filtrate was determined using AAS.

\section{Experimental procedures}

\subsection{Sample preparation}

A residual soil was obtained from a depth of 2 to $3 \mathrm{~m}$ below the ground surface. The soil was air-dried under laboratory conditions, after which pebbles and plant roots were removed. Only soil passing a $2.00 \mathrm{~mm}$ sieve was used in the EK experiments and other related tests. Then the sieved soil was mixed thoroughly in order to ensure homogeneity of the sample and kept in a securely tied large plastic bag to prevent or minimise the effects from the surrounding environment.

Soil samples with a dry density approximately $90 \% \rho_{\mathrm{dmax}}$ at its corresponding $w_{\text {opt }}$ were chosen as the basis of sample preparation for EK treatment. The $\rho_{\mathrm{dmax}}$ and $w_{\mathrm{opt}}$ were determined based on the standard Proctor compaction tests (BSI, 1990c). The diameter and length of each soil compartment of the EK cell utilised in this study were 100 and $50 \mathrm{~mm}$, respectively. Nonconductive silicon grease was thinly applied onto the inner surface of the soil compartment to avoid the formation of water film between the soil and the inner wall of the cylinder. This precaution was to ensure that water would only flow through the soil, not through channels between the soil and the wall of the cylinder during EK processing.

Every sample of soil and distilled water weighing about $666 \mathrm{~g}$ prepared for EK treatment was then poured into the soil compartment. A triaxial test frame was utilised to press the sample until a predetermined thickness of about $5.0 \mathrm{~cm}$ was achieved to obtain the required bulk density of $1695 \mathrm{~kg} / \mathrm{m}^{3}$. Then each sample was subjected to saturation.

\subsection{Electrokinetic experiments}

The EK experimental set-up is shown in Figure 3. Titanium meshes were utilised as the electrodes due to its high resistivity to corrosion (Berkeley and Pathmanaban, 1990). Flexible rubber tubes with an inner diameter of about $6 \mathrm{~mm}$ were utilised as inflow and outflow tubes. Glass tubes acting as gas vents were attached to the top of the electrolyte compartments to facilitate liberating gas from the system.

The only electrical parameter held constant in these EK experiments was the applied voltage, namely $30 \mathrm{~V}$. This value was chosen because attempts to apply lower voltages failed to produce flow after 2 days of EK treatment using distilled water as both the anolyte and catholyte. Four different open-anode and opencathode EK systems were employed, which consisted of

(a) distilled water as both the anolyte and catholyte (DW-DW)

(b) $1.0 \mathrm{~mol} / 1$ aluminium chloride as the anolyte and distilled water as the catholyte (Al-DW)

(c) $1.0 \mathrm{~mol} / \mathrm{l}$ calcium chloride solution as the anolyte and distilled water as the catholyte $(\mathrm{Ca}-\mathrm{DW})$. 


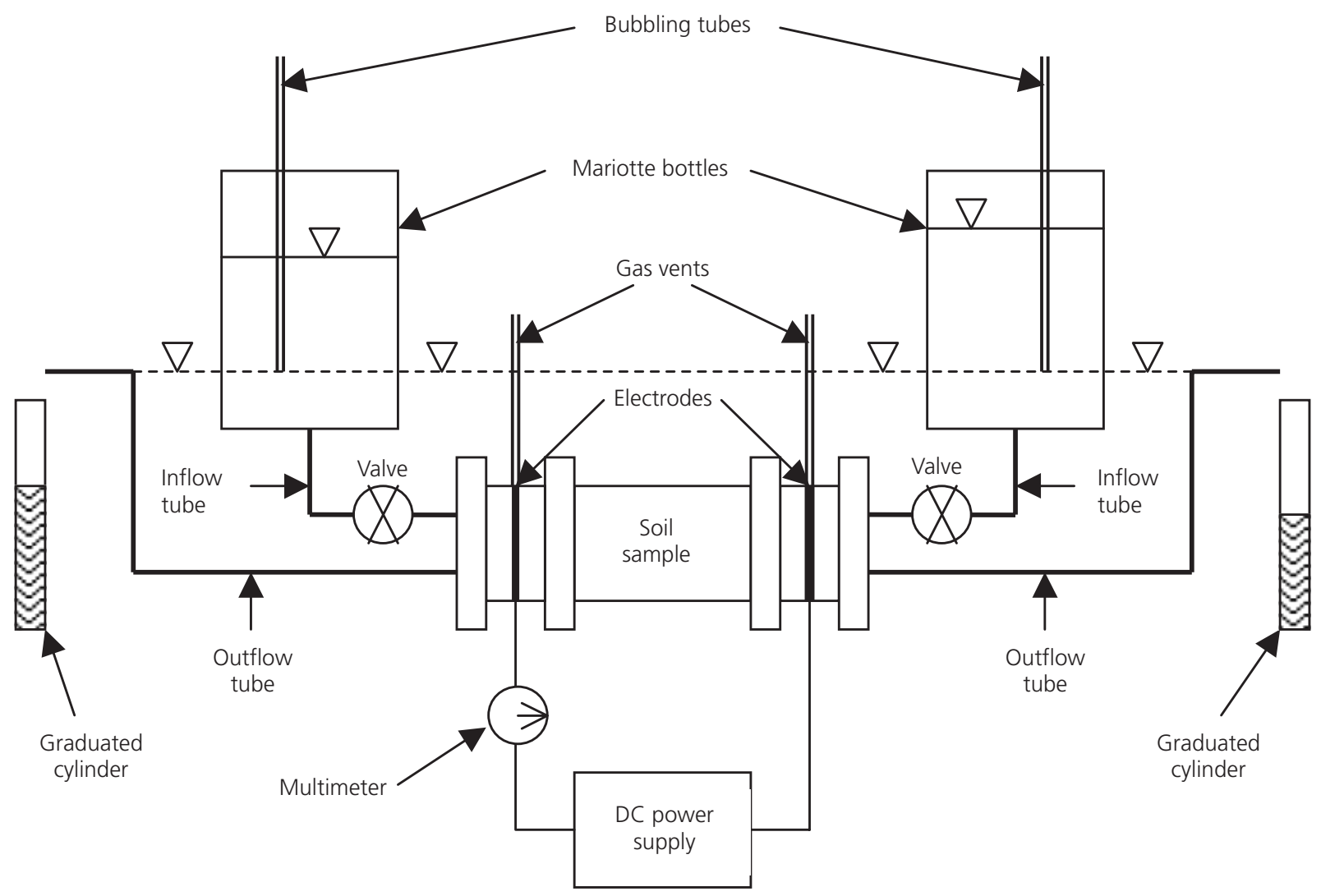

Figure 3. Schematic diagram of the EK experimental set-up

(d) distilled water as the anolyte and $1.0 \mathrm{~mol} / 1$ phosphoric acid as the catholyte (DW-PA).

Note that the left and right terms in each parenthesis represent the anolyte and catholyte, respectively. The selection of the chemical substances was based upon the types that have been utilised successfully on temperate soils, particularly kaolinite by previously mentioned researchers such as Gray (1970) and Ozkan et al. (1999). The duration of each EK treatment was $168 \mathrm{~h}$ (7 days) based on studies on electroremediation by Thevanayagam and Wang (1994), Taha (1996) and Park et al. (2005). Principally two samples were treated electrokinetically for each anolytecatholyte system, one for strength test and the other for consolidation test.

\subsection{Shear box tests}

After termination of EK processing, each treated sample was extruded and divided into two parts, namely the cathode side and the anode side. Then each part of the treated sample was subjected to strength test using a standard $60 \mathrm{~mm} \times$ $60 \mathrm{~mm} \times 20 \mathrm{~mm}$ shear box. A normal stress of $40 \mathrm{kPa}$ representing the in situ overburden stress from which the soil sample was obtained was applied to each specimen during shear. Note that the typical unit weight of soil in this region is within a range between 17 and $20 \mathrm{kN} / \mathrm{m}^{3}$. Each sample was subjected to quick test with the anticipation that failure would be reached within 5 to $10 \mathrm{~min}$ (BSI, 1990d). Thus, a shearing rate of $0.60 \mathrm{~mm} / \mathrm{min}$ was selected taking into account the shear box travelled into its full length. No attempts were made to cure the treated samples with the expectation that the treated samples should gain strength during or immediately after treatment.

\subsection{Compressibility tests}

After termination of EK processing, each treated sample was extruded and divided into two parts, namely the cathode side and the anode side. Then each part of the treated sample was subjected to a one-dimensional consolidation test in accordance with BS 1377: Part 5 (BSI, 1990e) using a $50 \mathrm{~mm}$ diameter and $20 \mathrm{~mm}$ high consolidation ring. As in the case of strength tests, no attempts were made to cure the treated samples.

\section{Results and discussion}

\subsection{Shear resistance}

Figures 4 and 5 show the plots of shear stresses against axial strains obtained from the direct shear tests on the samples within the vicinity of the anodes and cathodes, respectively. The ultimate shear stress values deduced from these figures are tabulated in Table 2. 


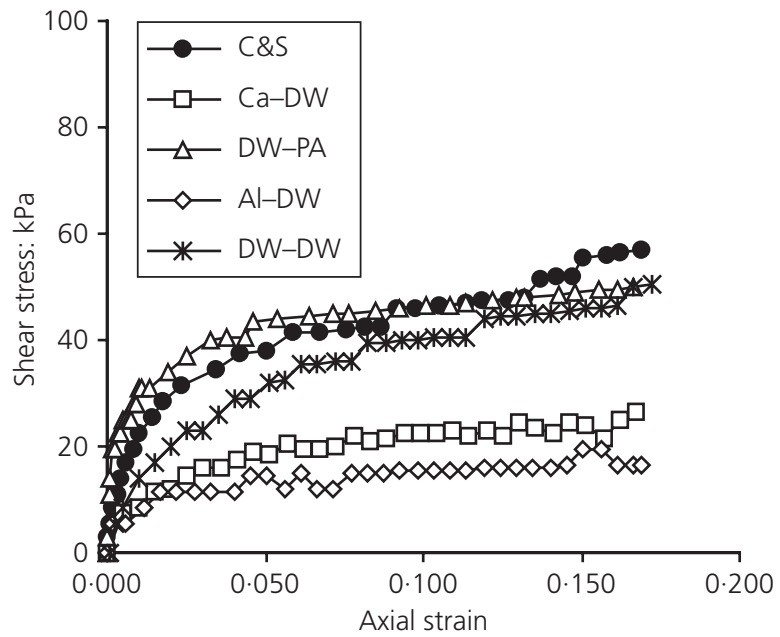

Figure 4. Shear resistances of samples after EK treatments near anodes. Note: terms on the left and right of hyphens indicate anolyte and catholyte, respectively: Al, aluminium chloride; C\&S, compacted and saturated (no EK treatment); DW, distilled water; Ca, calcium chloride; PA, phosphoric acid

To examine the effect of EK treatments, the shear resistance of the compacted and saturated sample (C\&S) that was not treated electrokinetically was utilised as a reference. For samples that did not exhibit any peak values of shear resistance under different strains, the ultimate shear stress was defined at the point where the slope of the shear stress-strain curve first reached a steady minimum value (Hanna and Abd El-Rahman, 1990).

\subsubsection{Compacted and saturated sample without EK treatment (C\&S)}

It was found that the average maximum shear stress of the $\mathrm{C} \& \mathrm{~S}$ samples was about $31 \mathrm{kPa}$ as shown in Figures 4 and 5. The shear resistance achieved was possibly due to cohesion, surface friction as well as the packing and orientation of the soil particles. The cohesion contributing to the shear resistance was the result of factors such as cementation and might be oxides of iron or aluminium (Blight, 1997; Fookes, 1997).

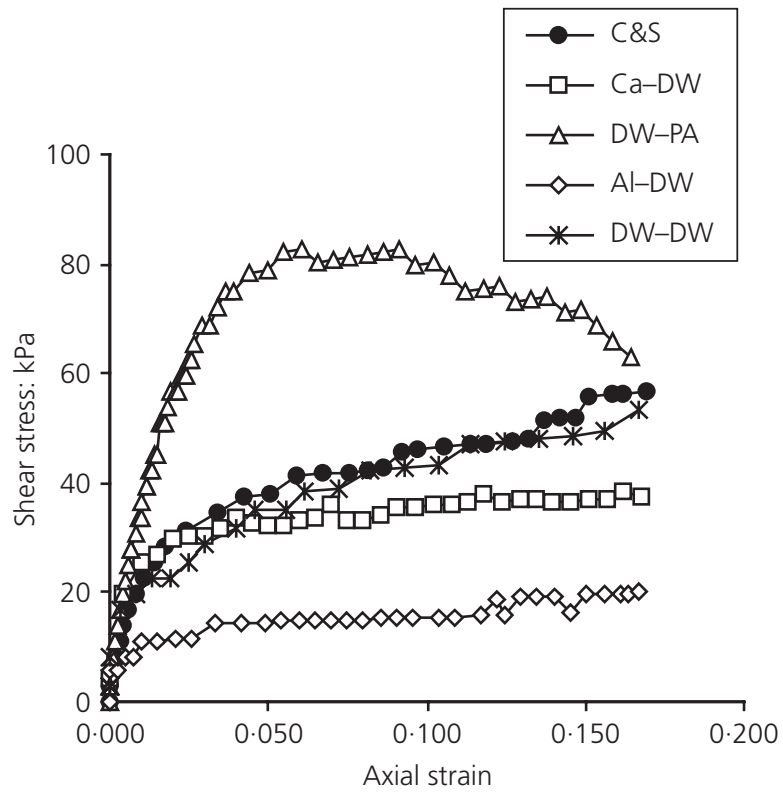

Figure 5. Shear resistances of samples after EK treatments near cathodes. Note: terms on the left and right of hyphens indicate anolyte and catholyte, respectively: Al, aluminium chloride; C\&S, compacted and saturated (no EK treatment); DW, distilled water; Ca, calcium chloride; PA, phosphoric acid

\subsubsection{DW-DW system}

Strength reduction was observed as certain compounds contributing to the strength of the soil would be ionised by the migration of $\mathrm{H}^{+}$across the soil samples (Ozkan et al., 1999) which led to an acidic environment due to the prolonged EK process. An acidic environment was also observed by Yeung and Hsu (2005) in a study on EK remediation. In addition, no cementation was anticipated to take place during the course of the experiment as cementation would only take place if suitable ions such as iron (Bell, 1975), calcium (Esrig and Gemeinhardt, 1967; Harton et al., 1967), or aluminium (Gray, 1970; Murayama and Mise, 1953) were present in the system.

\subsubsection{Ca-DW system}

Calcium ions will only react with clay minerals to form cementitious materials under a highly alkaline environment,

\begin{tabular}{lccrr}
\hline EK system & $\begin{array}{c}\text { Shear stress: kPa } \\
\text { (anode) }\end{array}$ & $\begin{array}{c}\text { \% increase } \\
\text { (anode) }\end{array}$ & $\begin{array}{c}\text { Shear stress, kPa } \\
\text { (cathode) }\end{array}$ & $\begin{array}{c}\text { \% increase } \\
\text { (cathode) }\end{array}$ \\
\hline C\&S (No EK) & 31 & 0 & 31 & 0 \\
DW-DW & 21 & -32 & 21 & -32 \\
Al-DW & 12 & -61 & 12 & -61 \\
Ca-DW & 15 & -52 & 31 & 0 \\
DW-PA & 35 & 13 & 83 & 168
\end{tabular}

Table 2. Ultimate values of shear resistance after EK processing 
namely a $\mathrm{pH}$ of 12.4 (Glendinning and Rogers, 1996). An environment with lower $\mathrm{pH}$ than 12.4 might cause calcium to remain ionic. As a result of the acidic environment within the vicinity of the anode area $(\mathrm{pH}=5 \cdot 3)$ and slightly alkaline near the cathode area $(\mathrm{pH}=7.53)$ due to the EK processing, no cementitious materials contributing to the strength increase were formed. Thus, the treated samples showed no improvement in shear resistance.

The results obtained in this study however contradicted those obtained by Harton et al. (1967) who employed EK to treat clay soil combined with the injection of calcium chloride and followed by the injection of aluminium sulfate. It can be deduced from their results that the electrokinetically injected calcium ions required secondary chemical injection to increase the strength of the treated soil.

Figures 6 and 7 show the images of the soil fabrics near the anode and cathode after $\mathrm{Ca}-\mathrm{DW}$ treatment, respectively. An electron microscope was employed to obtain images of the microstructures of the untreated and the EK-treated soils. Briefly, dried samples were coated with thin gold film using a sputter coater after which the gold-coated samples were placed in the vacuum compartment of the electron microscope to obtain their images at selected magnifications.

From Figure 6, it is believed that the coating materials (oxides of iron or aluminium) were dissolved due to the acidic environment or other chemical reactions that took place near the anode thus exposing the platy-shaped particles. On the other hand, Figure 7 shows large interconnected soil particles in the background besides randomly arranged small nodules in the foreground of the sample near the cathode. Ion exchanges that altered the property of the material as found by Esrig and Gemeinhardt (1967) might have led to such fabric or particle arrangements.

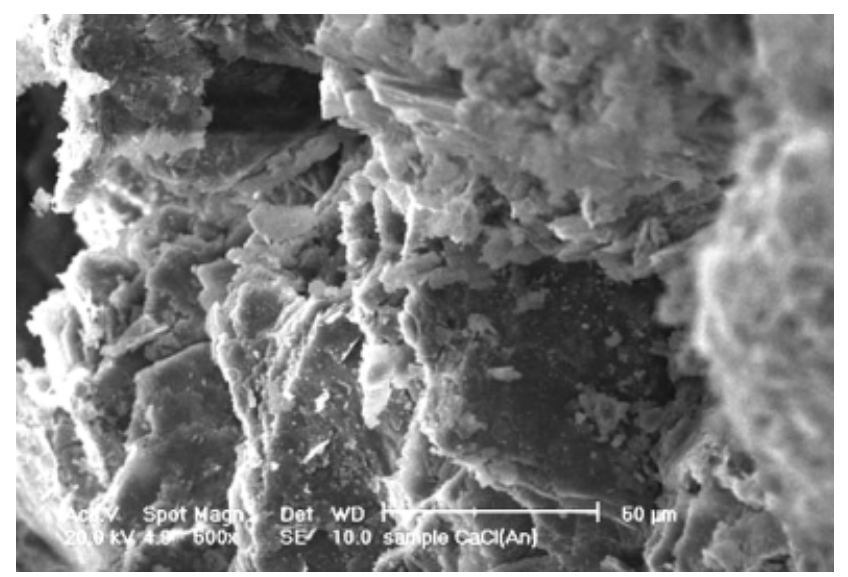

Figure 6. Image of soil fabric treated using Ca-DW system near anode

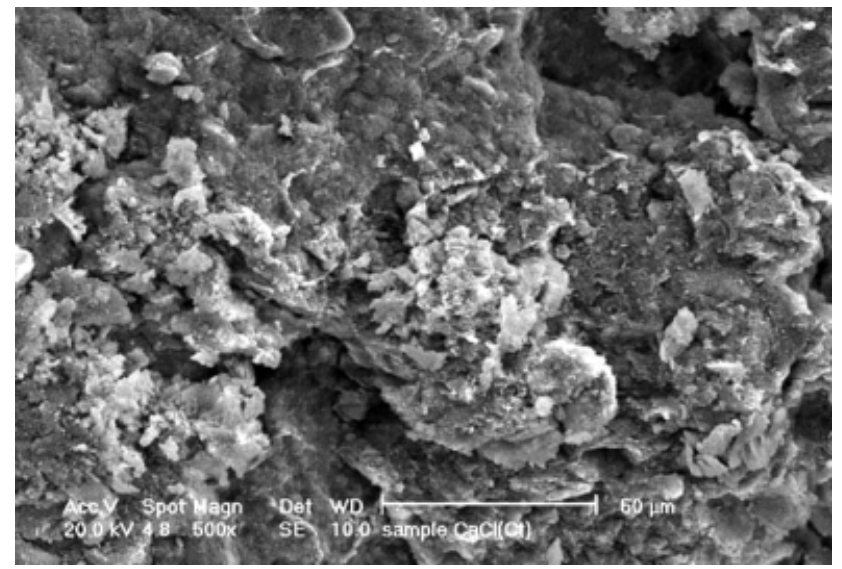

Figure 7. Image of soil fabric treated using Ca-DW system near cathode

\subsubsection{Al-DW system}

The strengths of the samples treated using this system were reduced both near the anode and the cathode. These observations contradicted the results obtained by Murayama and Mise (1953), Harton et al. (1967) and Gray (1970). Testing after the EK processing showed that the $\mathrm{pH}$ of the soil near the anode decreased from $5 \cdot 30$ to $3 \cdot 29$, whereas near the cathode the soil $\mathrm{pH}$ decreased to $3 \cdot 55$. Thus, the reduction of shear resistance of the treated soil was associated with the acidic environment in the soil. A previous study by Yamaguchi and Matsuda (1975) showed that neutral $\mathrm{pH}$ was necessary for full precipitation of aluminium hydroxide $\left(\mathrm{Al}(\mathrm{OH})_{3}\right)$ to take place.

The reduction in the soil $\mathrm{pH}$ at the cathode after treatment indicated that the amount of $\mathrm{H}^{+}$that migrated across the soil exceeded the quantity of the $\mathrm{OH}^{-}$that migrated towards the anode due to the prolonged EK treatment. Such phenomena took place since twice as much $\mathrm{H}^{+}$would be generated by the electrolysis of water at the anode in comparison with the generation of $\mathrm{OH}^{-}$at the cathode, and Acar et al. (1990) found that the acid front moved over a much greater distance than the base front. The acidic environment due to the migrated $\mathrm{H}^{+}$into the soil might have altered the chemistry of the pore fluid (Ozkan et al., 1999), which led to ionisation of certain minerals.

An earlier study by Gray (1970) showed that the utilisation of a $1 \%$ solution of $\mathrm{AlCl}_{3}$ as the anolyte and a $0.5 \%$ solution of $\mathrm{NaCl}$ as the catholyte to treat bentonitic and illitic soils were able to increase the strength of the treated soils. The strength increase was enhanced after the treated soils were cured for a month. In comparison with the previous work by Gray (1970), note that the residual soil samples were not cured after EK treatment in which $1.0 \mathrm{~mol} / 1 \mathrm{AlCl}_{3}$ and distilled water were used as the anolyte and catholyte, respectively. Thus, a curing period might be required so that hydroxides of aluminium compounds would harden and increase the strength of the treated soils in addition to introducing secondary chemical during the EK processing. 
Electrokinetic treatment on a tropical

residual soil

Ahmad, Taha and Kassim
On the other hand, Murayama and Mise (1953) showed that the strengthening of clay soils treated electrokinetically by the injection of $\mathrm{Al}^{3+}$ would only take place once the precipitated $\mathrm{Al}(\mathrm{OH})_{3}$ was dehydrated to become bauxite $(\mathrm{AlO}(\mathrm{OH}))$ and alumina $\left(\mathrm{Al}_{2} \mathrm{O}_{3}\right)$ as described by the following equation

3. \begin{tabular}{lllll}
$\mathrm{Al}(\mathrm{OH})_{3}$ & $\underset{\mathrm{H}_{2} \mathrm{O}}{\rightarrow}$ & $\mathrm{AlO}(\mathrm{OH})$ & $\underset{-\mathrm{H}_{2} \mathrm{O}}{\rightarrow}$ & $\mathrm{Al}_{2} \mathrm{O}_{3}$ \\
\hline
\end{tabular}

It was suspected that the $\mathrm{Al}(\mathrm{OH})_{3}$ within the treated residual soil near the cathode in this study remained as gel as no dehydration process took place after the completion of EK treatment. Such compound could cause lubrication between the soil particles during shear, resulting in the strength reductions.

Figures 8 and 9 illustrate the images of the soil fabrics of the treated sample near the anode and cathode, respectively. Near the anode, stacks of flaky particles and small nodules are visible

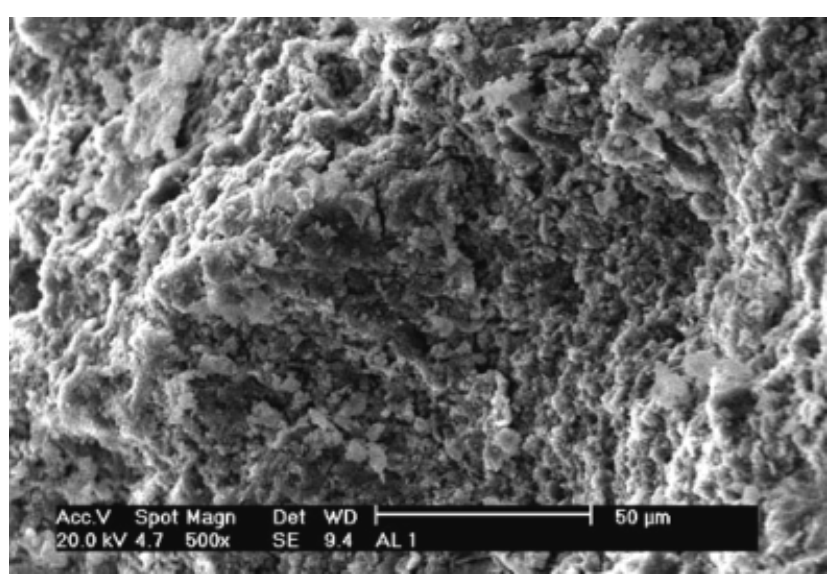

Figure 8. Image of fabric after Al-DW treatment near the anode

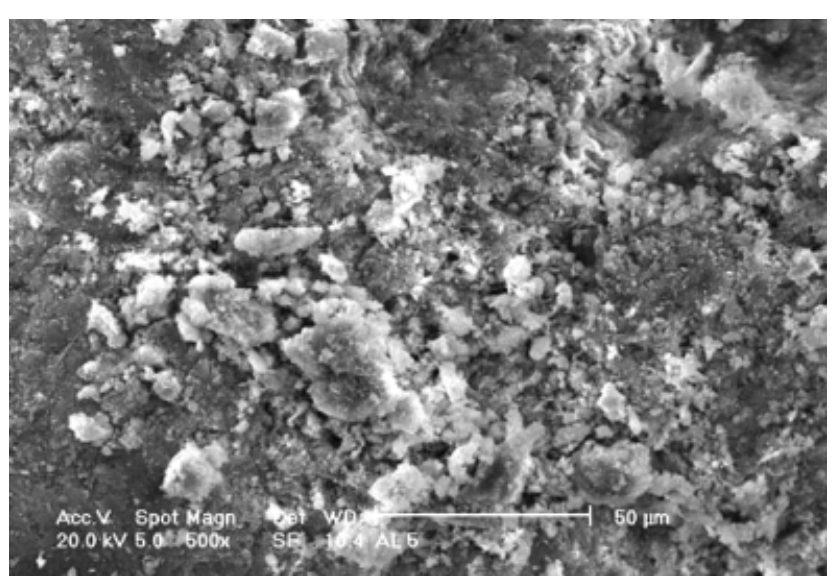

Figure 9. Image of fabric after Al-DW treatment near the cathode within the treated soil matrix. Dissolution or ionisation of the coating materials and other compounds or precipitates due to the acidic environment as stated previously might be the reason for the exposed flaky particles.

Near the cathode on the other hand, some cemented soil particles can be observed in the background of the image with randomly arranged and irregularly shaped nodules as well as flaky-shaped particles in the foreground. Such coating materials might be compounds containing $\mathrm{Al}^{3+}$. Note that such compounds did not contribute to strength increase as those compounds were in hydrated forms.

\subsubsection{DW-PA system}

The shear resistances of the soil after EK treatment increased to 35 and $83 \mathrm{kPa}$ near the anode and cathode, respectively. These values represent strength increases of $13 \%$ near the anode and $168 \%$ near the cathode. The formation of phosphate compounds as coating and cementing agents might be the most probable reason for the high value of shear resistance achieved by the treated soil. It was suspected that the low amount of phosphate within the vicinity of the anode resulted only in a slight increase in shear resistance in comparison with the significant increase near the cathode.

As the soil used in this study contained aluminium and iron in addition to the acidic condition of the soil before and after EK treatment, it was suspected that aluminium or iron phosphates were formed contributing to the increase in shear resistance after the DW-PA treatment. It was anticipated that $\mathrm{Al}^{3+}$ was released due to the acidification of residual soil (Gidigasu, 1976). Hence, the most probable compound formed as a result of the injection of phosphate ions was that of hydrated aluminium phosphate. Attempts made on the basis of an XRD study to identify the formation of new minerals or compounds on the DW-PA treated samples immediately after completion of the processing were unsuccessful. It was hypothesised that the new and fresh cementing compounds were in a non-crystalline or an amorphous form.

Figures 10 and 11 illustrate the images of the samples near the anode and cathode, respectively. Near the anode, it can be seen that the soil in the background was tightly packed with some voids as shown by the dark spots, whereas various sizes of nodules with irregular shapes are visible in the foreground. Near the cathode, the soil particles were interconnected and coated by phosphate compounds to form large particles with some large voids and nodules of various sizes. Ion exchange, acidification, formation of phosphate compounds or other chemical reactions resulting from the EK treatment might be the possible reasons for such soil fabrics.

\subsection{Compressibility}

As the initial void ratios of the treated samples were slightly different from each other due to sampling procedures, normalised void ratios were utilised in the construction of the compression 
Electrokinetic treatment on a tropical

residual soil

Ahmad, Taha and Kassim

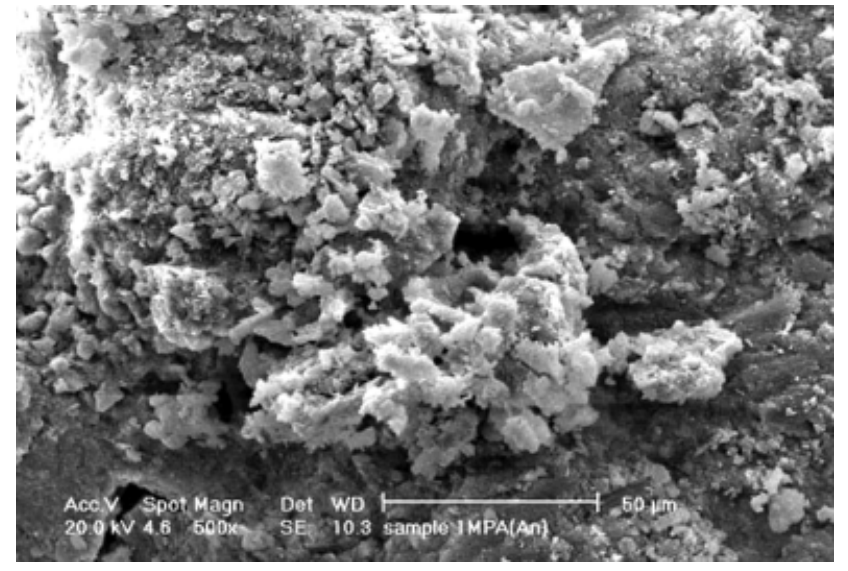

Figure 10. Image of fabric of DW-PA treated sample near anode

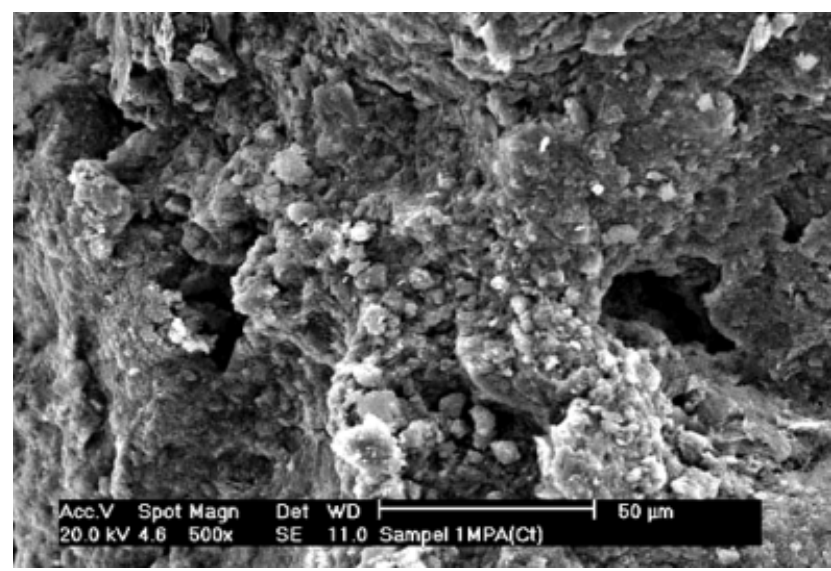

Figure 11. Image of fabric of DW-PA treated sample near cathode

curves. The normalised values were obtained by dividing the void ratios at different stresses by the initial void ratio of the respective samples. Consequently, all compression curves had the initial normalised void ratio of unity. The discussion hereafter will be based on the results from consolidation tests as shown in Figures 12 and 13.

As disturbed samples were utilised for the consolidation tests, yield stresses $\left(\sigma_{\mathrm{y}}\right)$ will be referred to in the discussion instead of pre-consolidation pressures $\left(\sigma_{\mathrm{c}}\right)$. The selection of the yield stress values was based on the definition of maximum curvature (Hanna and Abd El-Rahman, 1990). The compression curve of the compacted and saturated sample (C\&S) that was not treated electrokinetically will be utilised as a reference to any changes resulting from the EK treatments. Table 3 summarises the relevant indices and coefficients obtained from the conducted consolidation tests.

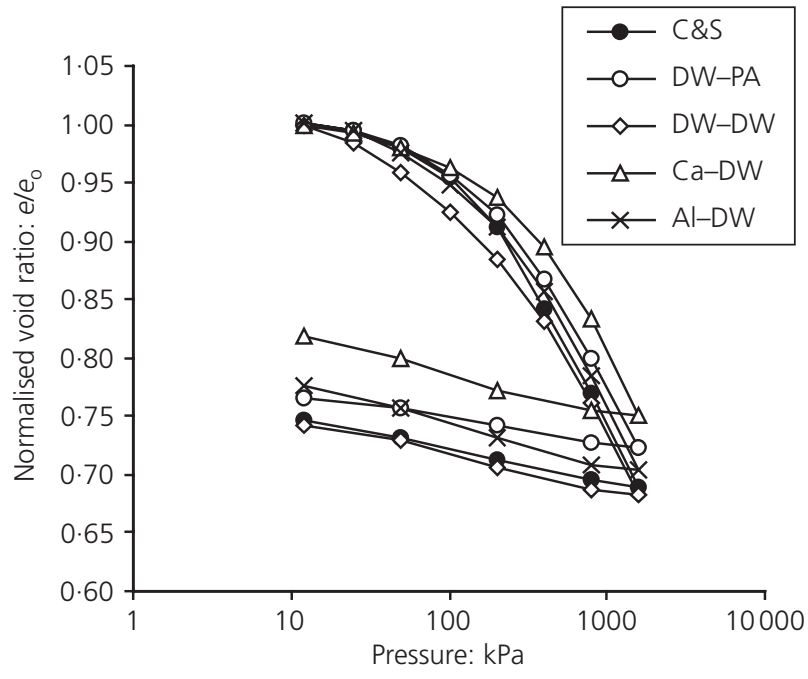

Figure 12. Normalised compression curves of electrokinetically treated samples near anodes

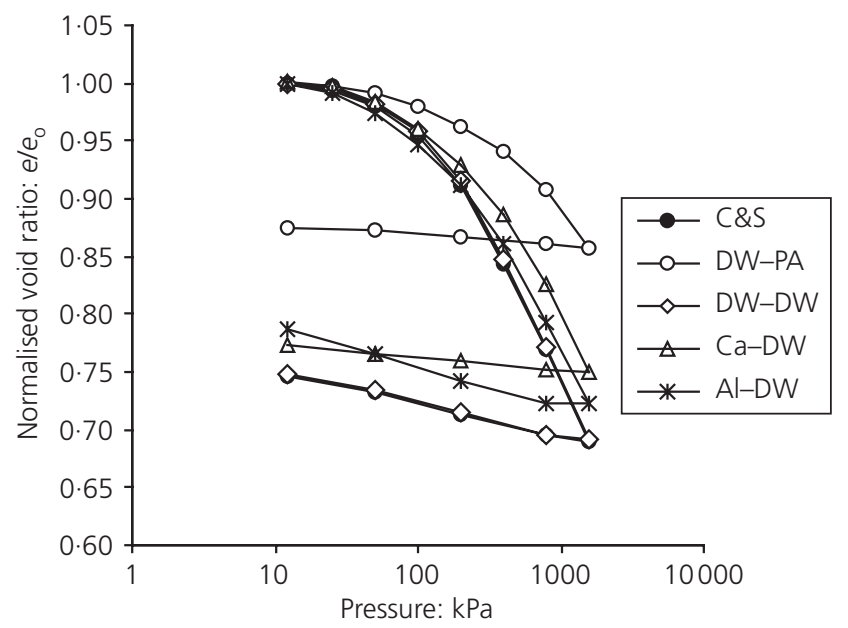

Figure 13. Normalised compression curves of electrokinetically treated samples near cathodes.

\subsubsection{Compacted and saturated sample without EK treatment (C\&S)}

It can be seen from those curves that the compression index $C_{\mathrm{c}}$ and swelling index $C_{\mathrm{s}}$ were 0.25 and 0.03 , respectively. In an earlier study on a residual laterite soil, Vargas (see Gidigasu, 1976) obtained $C_{\mathrm{c}}$ and $C_{\mathrm{s}}$ values of $0 \cdot 22$ and $0 \cdot 03$, respectively. Such $C_{\mathrm{c}}$ values are considered as moderate to intermediate compressibility (Mitchell, 1993).

Figure 12 shows that the $\sigma_{\mathrm{y}}$ of the soil used in this study was approximately $100 \mathrm{kPa}$, higher than the maximum overburden pressure of about $60 \mathrm{kPa}$ considering the soil sample was obtained from 2 to $3 \mathrm{~m}$ below the ground surface. Hence, the soil 


\begin{tabular}{|c|c|c|c|c|c|}
\hline Treatment systems & $C \& S$ & DW-DW & Ca-DW & Al-DW & DW-PA \\
\hline$C_{c(\text { anode })}$ & 0.25 & 0.24 & 0.23 & 0.25 & 0.24 \\
\hline$C_{c(\text { cath })}$ & $0 \cdot 25$ & 0.25 & $0 \cdot 24$ & 0.23 & $0 \cdot 14$ \\
\hline$C_{s \text { (anode) }}$ & 0.03 & 0.03 & 0.03 & 0.04 & 0.02 \\
\hline$C_{s(\text { cath })}$ & 0.03 & 0.03 & 0.01 & 0.04 & 0.01 \\
\hline$C_{v(\text { anode })}: \mathrm{m}^{2} /$ year & $4 \cdot 16-7 \cdot 53$ & $4 \cdot 41-7 \cdot 91$ & $1 \cdot 36-4 \cdot 33$ & $2 \cdot 73-5 \cdot 46$ & $3 \cdot 48-9 \cdot 20$ \\
\hline$c_{v(\text { cath })}: m^{2} /$ year & $4 \cdot 16-7 \cdot 53$ & $4 \cdot 26-7 \cdot 31$ & $1 \cdot 13-9 \cdot 44$ & $9 \cdot 8-20 \cdot 3$ & $2 \cdot 01-7 \cdot 71$ \\
\hline$m_{\mathrm{v}(\text { anode })} 10^{-4}: \mathrm{m}^{2} / \mathrm{kN}$ & $1 \cdot 49$ & $1 \cdot 4$ & 0.90 & $1 \cdot 16$ & $1 \cdot 23$ \\
\hline$m_{\mathrm{v}(\text { cath })} 10^{-4}: \mathrm{m}^{2} / \mathrm{kN}$ & $1 \cdot 49$ & $1 \cdot 26$ & 1.03 & $1 \cdot 12$ & $1 \cdot 2$ \\
\hline$k_{\text {(anode) }} 10^{-10}: \mathrm{m} / \mathrm{s}$ & $1 \cdot 93-3 \cdot 50$ & $1 \cdot 92-3 \cdot 44$ & $0 \cdot 38-1 \cdot 21$ & $0.98-1.97$ & $1 \cdot 33-3 \cdot 52$ \\
\hline$k_{\text {(cath) }} 10^{-10}: \mathrm{m} / \mathrm{s}$ & $1 \cdot 93-3 \cdot 50$ & $1 \cdot 67-2 \cdot 87$ & $0.36-3.02$ & $3 \cdot 41-7 \cdot 07$ & $0.75-2.88$ \\
\hline$\sigma_{\mathrm{y}(\text { anode })}: \mathrm{kPa}$ & 100 & 25 & 200 & 50 & 200 \\
\hline$\sigma_{\mathrm{y}(\mathrm{cath})}: \mathrm{kPa}$ & 100 & 100 & 100 & 100 & 400 \\
\hline
\end{tabular}

Note: Determinations of $m_{v}$ and $k$ were based on 200-800 kPa stress range.

Table 3. Values of indices, coefficients and yield stresses

was apparently 'overconsolidated' which could result from several factors such as changes in vertical stress, particle arrangements and porewater pressure during sample preparations, drying to evaporation and natural cementation due to carbonates (Mitchell, 1993).

A wide stress range between 200 and $800 \mathrm{kPa}$ was arbitrarily selected to observe variation in values of coefficients of consolidation $\left(c_{\mathrm{v}}\right)$ and hydraulic conductivity $(k)$, if any. The values of $c_{\mathrm{v}}$ varied between 4.16 and $7.53 \mathrm{~m}^{2} /$ year and the average volume compressibility $\left(m_{\mathrm{v}}\right)$ was $1.49 \times 10^{-4} \mathrm{~m}^{2} / \mathrm{kN}$. With the availability of $c_{\mathrm{v}}$ and $m_{\mathrm{v}}$ values, the $k$ values of the untreated soil during consolidation were correlated and determined to fall within a narrow range between $1.93 \times 10^{-10}$ and $3.50 \times 10^{-10} \mathrm{~m} / \mathrm{s}$. These values are two orders of magnitude lower than that obtained directly using variable head permeability tests as shown in Table 1. Changes in particle arrangements and pores sizes, and the bending and crushing of soil particles during the consolidation process were the main reasons for such differences.

\subsubsection{EK-treated samples}

It can be seen from Table 3 that the $C_{\mathrm{c}}$ of the DW-PA treated sample near the cathode decreased significantly to $0 \cdot 14$ in comparison with that of the C\&S sample. The formation of phosphate compounds as coating and cementing agents that were highly resistance to interparticle sliding might be the most probable reason for the reduced value of $C_{\mathrm{c}}$. The reduction in the $C_{\mathrm{c}}$ also might be associated with the pore water chemistry that depressed the double layer (Mitchell, 1993).

In addition, the $\sigma_{\mathrm{y}}$ of the DW-PA-treated soil near the anode was increased to $200 \mathrm{kPa}$, whereas near the cathode it was increased by about $300 \%$ to $400 \mathrm{kPa}$. Such effects might also be caused by the cementation and coating of phosphate compounds on the soil particles. These compounds encapsulated and linked the soil particles together to form large soil grains and exerted internal effective stress under which the soil was consolidated due to the confinement of the sample in the EK cells. The samples were therefore virtually 'overconsolidated' by the EK processing, and this is the reason why the effects of the treatment are permanent (Lo et al., 1991).

The acidic environment generated by the EK process that dissolved certain compounds and increased the lubrication effects between soil particles (Ghazali, 1981) might be the reason for the reductions in $\sigma_{\mathrm{y}}$ values near the anodes of the DW-DW and $\mathrm{Al}-$ DW-treated samples. Swelling of the treated sample near the anode due to direct contact with the anolyte (Taha, 1996) and the released stress during sampling were additional reasons for the reduced $\sigma_{\mathrm{y}}$.

No significant changes were observed in other parameters after each EK treatment. For instance, the $k$ values of the EK-treated samples obtained indirectly from consolidation tests were two orders of magnitude lower than that of the EK-treated samples obtained directly based on variable head permeability tests. Overall, the slight changes were mostly associated with the pore water chemistry resulting from complex, dynamic and interrelated chemical processes during EK treatment. Ionisation and desorption of certain ions (Ozkan et al., 1999) also might affect the compressibility and the associated indices and coefficients of the treated soil.

\section{Conclusions}

Electrokinetic treatments were conducted on a tropical granitic residual soil, after which direct shear and consolidation tests were performed on the treated soil samples. The conclusions that can be drawn from this study are listed here. 
(a) The introduction of phosphate ions significantly increased and decreased the shear resistance and the compression index of the treated soil near the cathode, respectively due to the formation of phosphate compounds.

(b) The electrokinetically injected calcium and aluminium ions were unable to increase the shear resistance or to reduce the compression indices of the treated soils since the calcium remained ionic whereas the formation of aluminium gel lubricated the soil particles due to the acidic environment.

(c) The difference in terms of soil parameters and indices near the anode than those near the cathode after each treatment showed the non-homogeneity of chemical precipitation throughout the treated sample.

\section{REFERENCES}

Acar YB, Gale RJ, Hamed J and Putnam G (1990)

Electrochemical processing of soils; theory of $\mathrm{pH}$ gradient development by diffusion and linear convection. Journal of Environmental Science and Health, Part (a); Environmental Science 25(6): 687-714.

Barker JE, Rogers CDF, Boardman DI and Peterson J (2004) Electrokinetic stabilisation: an overview and case study. Ground Improvement 8(2): 47-58.

Bell FG (ed.) (1975) Methods of Treatment of Unstable Ground. Newnes-Butterworths, London, UK, pp. 26-36.

Berkeley KGC and Pathmanaban S (1990) Cathodic Protection of Reinforcement Steel in Concrete. Butterworths, London. p. 121.

Berry LG (ed.) (1974) Selected Powder Diffraction Data for Minerals. Joint Committee on Powder Diffraction Standards, Philadephia, PA, USA.

Blight BE (ed.) (1997) Origin and formation of residual soils. In Mechanics of Residual Soil. Balkema, Rotterdam, the Netherlands, pp. 1-15.

Brady NC and Weil RR (1996) The Nature and Properties of Soils, 11 th edn. Prentice Hall, Englewood Cliffs, NJ, USA.

BSI (British Standards Institution) (1990a) BS 1377: Part 2: Classification tests. BSI, Milton Keynes.

BSI (British Standards Institution) (1990b) BS 1377: Part 3: Chemical and Electro-chemical tests. BSI, Milton Keynes.

BSI (British Standards Institution) (1990c) BS 1377: Part 4: Compaction-related tests. BSI, Milton Keynes.

BSI (British Standards Institution) (1990d) BS 1377: Part 7: Shear Strength tests (Total Stress). BSI, Milton Keynes.

BSI (British Standards Institution) (1990e) BS 1377: Part 5: Compressibility, Permeability and Durability tests. BSI, Milton Keynes.

Chappell BA and Burton PL (1975) Electro-osmosis applied to unstable embankment. Journal of the Geotechnical Engineering Division, ASCE 101(8): 733-739.

Esrig MI (1968) Pore pressures, consolidation and electrokinetics. Journal of the Soil Mechanics and Foundation Division ASCE 94(4): 899-921.
Esrig MI and Gemeinhardt JP Jr (1967) Electrokinetic stabilization of an illitic clay. Journal of the Soil Mechanics and Foundation Division, ASCE 93( SM3): 109-128.

Fetzer CA (1967) Electro-osmotic stabilization of West Branch Dam. Journal of the Soil Mechanics and Foundation Division, ASCE 93(SM4): 85-106.

Fookes PG (ed.) (1997) Geological Society Professional Handbook: Tropical Residual Soils. The Geological Society, London, UK.

Ghazali MF (1981) Soil Stabilization by Chemical Additives. PhD thesis, The University of Washington, USA.

Gidigasu MD (1976) Laterite Soil Engineering: Pedogenesis and Engineering Principles. Elsevier, Amsterdam, the Netherlands.

Glendinning S and Rogers CDF (1996) Deep stabilisation using lime. In Lime Stabilisation (Rogers et al. (eds)). Thomas Telford, London, UK, pp. 127-136.

Gray DH (1970) Electrochemical hardening of clay soils. Géotechnique 20(1): 81-93.

Hanna A and Abd El-Rahman M (1990) Ultimate bearing capacity of triangular shell strip footings on sand. Journal of Geotechnical Engineering, ASCE 116(12): 1851-1863.

Harton JH, Hamid S, Abi-Chedid E and Chilingar GV (1967) Effects of electrochemical treatment on selected physical properties of a clayey silt. In Engineering Geology 2(3). Elsevier, Amsterdam, the Netherlands, pp. 191-196.

Hausmann MR (1990) Engineering Principles of Ground Modifications. McGraw-Hill, New York, USA, p. 286. Head KH (1982) Manual of Soil Laboratory Testing Volume 2: Permeability, Shear Strength and Compressibility Tests, Pentech Press, London, UK.

Hesse PR (1972) A Textbook of Soil Chemical Analysis. Chemical Publishing, New York, USA.

Johnston IW and Butterfield R (1977) A laboratory investigation of soil consolidation by electro-osmosis. Australian Geomechanics Journal G7: 21-32.

Lo KY and Ho KS (1991) Field test of electroosmotic strengthening of soft sensitive clay. Canadian Geotechnical Journal 28(2): 74-83.

Lo KY, Inculet II and Ho KS (1991) Electroosmotic strengthening of sensitive clays. Canadian Geotechnical Journal 28(2): $62-73$.

Mitchell JK (1993) Fundamentals of Soil Behavior, 2nd edn. Wiley, New York, USA.

Moris N and Singh MM (1980) Manual of Laboratory Methods of Chemical Soil Analysis. Rubber Research Institute of Malaysia, Kuala Lumpur.

Murayama S and Mise T (1953) On the electrochemical consolidation of soil using aluminium electrodes. Proceedings of the 3rd International Conference on Soil Mechanics and Foundation Engineering, Zurich, 156-159.

Othman MZ and Shafii F (1990) Effects of current modes in electro-osmosis treatment of clayey soils. Proceedings of the 10th Southeast Asian Geotechnical Conference, Taipei, Taiwan, 115-120. 
Ozkan S, Gale RJ and Seals RK (1999) Electrokinetic stabilization of kaolinite by injection of $\mathrm{Al}^{3+}$ and $\mathrm{PO}_{4}{ }^{3-}$ ions. Ground Improvement 3(4): 135-144.

Park J-Y, Kim S-J, Lee Y-J, Baek K and Yang J-W (2005) EK-Fenton Process for removal of phenanthrene in a two-dimensional soil system. Engineering Geology 77(3): 217-224.

Sridharan A (1988) General report - Technical session II: Engineering properties of tropical soils. Proceedings of the 2nd International Conference on Geomechanics in Tropical Soils, Singapore. Balkema, Rotterdam, the Netherlands, $42-56$.

Taha MR (1996) Micellar Electrokinetic Remediation of TNT from Soil. PhD thesis, The Louisiana State University, USA. Thevanayagam S and Wang J (1994) Flow behavior during electrokinetic soil decontamination. Proceedings of the 1st International Congress on Environmental Geotechnics, Edmonton, Canada. Balkema, Rotterdam, the Netherlands, pp. 379-385.

Yamaguchi T and Matsuda S (1975) Stabilization of sand feasible to liquefaction by means of a kind of grouting applying electroosmosis. Proceedings of the Technical Session of the Symposium on Recent Developments in the Analysis of Soil Behaviour and their Applications to Geotechnical Structures. Unisearch Ltd. The University of New South Wales, Australia, pp. 411-421.

Yeung AT and Hsu C (2005) Electrokinetic remediation of cadmium-contaminated clay. Journal of Environmental Engineering, ASCE 131(2): 298-304.

\section{WHAT DO YOU THINK?}

To discuss this paper, please email up to 500 words to the editor at journals@ice.org.uk. Your contribution will be forwarded to the author(s) for a reply and, if considered appropriate by the editorial panel, will be published as a discussion in a future issue of the journal.

Proceedings journals rely entirely on contributions sent in by civil engineering professionals, academics and students. Papers should be 2000-5000 words long (briefing papers should be 1000-2000 words long), with adequate illustrations and references. You can submit your paper online via www.icevirtuallibrary.com/content/journals, where you will also find detailed author guidelines. 